NASA/TM-2003-212506

\title{
Monte Carlo Simulation of Sudden Death Bearing Testing
}

Brian L. Vlcek

Georgia Southern University, Statesboro, Georgia

Robert C. Hendricks and Erwin V. Zaretsky

Glenn Research Center, Cleveland, Ohio 
Since its founding, NASA has been dedicated to the advancement of aeronautics and space science. The NASA Scientific and Technical Information (STI) Program Office plays a key part in helping NASA maintain this important role.

The NASA STI Program Office is operated by Langley Research Center, the Lead Center for NASA's scientific and technical information. The NASA STI Program Office provides access to the NASA STI Database, the largest collection of aeronautical and space science STI in the world. The Program Office is also NASA's institutional mechanism for disseminating the results of its research and development activities. These results are published by NASA in the NASA STI Report Series, which includes the following report types:

- TECHNICAL PUBLICATION. Reports of completed research or a major significant phase of research that present the results of NASA programs and include extensive data or theoretical analysis. Includes compilations of significant scientific and technical data and information deemed to be of continuing reference value. NASA's counterpart of peerreviewed formal professional papers but has less stringent limitations on manuscript length and extent of graphic presentations.

- TECHNICAL MEMORANDUM. Scientific and technical findings that are preliminary or of specialized interest, e.g., quick release reports, working papers, and bibliographies that contain minimal annotation. Does not contain extensive analysis.

- CONTRACTOR REPORT. Scientific and technical findings by NASA-sponsored contractors and grantees.
- CONFERENCE PUBLICATION. Collected papers from scientific and technical conferences, symposia, seminars, or other meetings sponsored or cosponsored by NASA.

- SPECIAL PUBLICATION. Scientific, technical, or historical information from NASA programs, projects, and missions, often concerned with subjects having substantial public interest.

- TECHNICAL TRANSLATION. Englishlanguage translations of foreign scientific and technical material pertinent to NASA's mission.

Specialized services that complement the STI Program Office's diverse offerings include creating custom thesauri, building customized databases, organizing and publishing research results ... even providing videos.

For more information about the NASA STI Program Office, see the following:

- Access the NASA STI Program Home Page at http://www.sti.nasa.gov

- E-mail your question via the Internet to help@sti.nasa.gov

- Fax your question to the NASA Access Help Desk at 301-621-0134

- Telephone the NASA Access Help Desk at 301-621-0390

- Write to:

NASA Access Help Desk

NASA Center for AeroSpace Information 7121 Standard Drive

Hanover, MD 21076 
NASA/TM-2003-212506

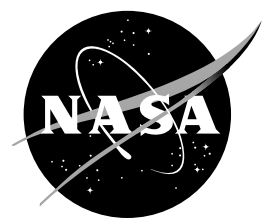

\section{Monte Carlo Simulation of Sudden Death Bearing Testing}

Brian L. Vlcek

Georgia Southern University, Statesboro, Georgia

Robert C. Hendricks and Erwin V. Zaretsky

Glenn Research Center, Cleveland, Ohio

Prepared for the

International Joint Tribology Conference

cosponsored by the Society of Tribologists and Lubrication Engineers and the Tribology Division of the American Society of Mechanical Engineers International Ponte Vedra, Florida, October 27-29, 2003

National Aeronautics and

Space Administration

Glenn Research Center 


\section{Acknowledgments}

The authors would like to acknowledge the contributions of Gregory Hickman, Georgia Southern University, for generating many of the spreadsheets used in the Monte Carlo analysis in this paper.

Available from

NASA Center for Aerospace Information 7121 Standard Drive

Hanover, MD 21076
National Technical Information Service 5285 Port Royal Road Springfield, VA 22100

Available electronically at http:/ /gltrs.grc.nasa.gov 


\title{
MONTE CARLO SIMULATION OF SUDDEN DEATH BEARING TESTING
}

\author{
Brian L. Vlcek \\ Georgia Southern University \\ Statesboro, Georgia 30460-8045 \\ Robert C. Hendricks and Erwin V. Zaretsky \\ National Aeronautics and Space Administration \\ Glenn Research Center \\ Cleveland, Ohio 44135
}

\begin{abstract}
Monte Carlo simulations combined with sudden death testing were used to compare resultant bearing lives to the calculated bearing life and the cumulative test time and calendar time relative to sequential and censored sequential testing. A total of 30960 virtual 50-mm bore deep-groove ball bearings were evaluated in 33 different sudden death test configurations comprising 36, 72, and 144 bearings each. Variations in both life and Weibull slope were a function of the number of bearings failed independent of the test method used and not the total number of bearings tested. Variation in $\boldsymbol{L}_{\mathbf{1 0}}$ life as a function of number of bearings failed were similar to variations in life obtained from sequentially failed real bearings and from Monte Carlo (virtual) testing of entire populations. Reductions up to 40 percent in bearing test time and calendar time can be achieved by testing to failure or the $\boldsymbol{L}_{50}$ life and terminating all testing when the last of the predetermined bearing failures has occurred. Sudden death testing is not a more efficient method to reduce bearing test time or calendar time when compared to censored sequential testing.
\end{abstract}

\section{NOMENCLATURE}

CD dynamic load capacity, N (lbf)

C censored or suspended test

c stress-life exponent

e Weibull slope

h exponent

$\boldsymbol{j} \quad$ mean order number

$\mathbf{L} \quad$ life, number of stress cycles or $\mathrm{hr}$

$\boldsymbol{L}_{\mathbf{1 0}} \quad 10$-percent life or life at which 90 percent of a population survives, number of stress cycles or $\mathrm{hr}$

$\boldsymbol{L}_{\beta} \quad$ characteristic life or life at which 63.2 percent of population fails, number of stress cycles or $\mathrm{hr}$

$\boldsymbol{m} \quad$ total number of bearing testers used simultaneously

$N \quad$ life, number of stress cycles

$\boldsymbol{n} \quad$ number of bearings or number $(\boldsymbol{m} \times \boldsymbol{r})$ of subgroups with a single failed bearing

Peq equivalent radial load, N (lbf)

p load-life exponent

$\boldsymbol{r} \quad$ number of failures or number of subgroups of $\boldsymbol{m}$ bearings

$\boldsymbol{S} \quad$ probability of survival, fraction or percent

$\boldsymbol{V} \quad$ stressed volume, $\mathrm{m}^{3}$, (in. $^{3}$ )

$Z_{o} \quad$ depth to the orthogonal shearing stress

$\boldsymbol{l}_{0} \quad$ orthogonal shearing stress, GPa (ksi) 


\begin{tabular}{ll}
\multicolumn{2}{l}{ Subscripts } \\
$i$ & $\mathrm{i}^{\text {th }}$ component or bearing \\
ir & inner race \\
$L$ & lower limit \\
$n$ & number of components \\
or & outer race \\
$r e$ & rolling elements \\
sys & system \\
up & upper limit
\end{tabular}

$\begin{array}{ll}\text { Abbreviations } \\ \text { calc } & \text { calculated } \\ \text { max } & \text { maximum } \\ \text { min } & \text { minimum }\end{array}$

\section{Definitions}

calculated life $=$ The life obtained using the Lundberg-Palmgren life equations

resultant life $=$ The life obtained from the Weibull analysis of bearing systems generated by a Monte Carlo technique

\section{INTRODUCTION}

Predicting and experimentally validating rolling-element bearing life is a complex, time- consuming, and costly task. Many investigators believe that there is no alternative to testing an entire fixed population of components to failure when accurately determining the life of their product. Sudden death testing, however, is considered a technique by which product development test time is shortened by running concurrent tests and not necessarily running all of the tests to failure. The question becomes whether the reliability (accuracy and precision) of the resultant life is influenced by the chosen testing method.

One needs to go back to the classic work of L.G. Johnson (1) to find early explanations of methods for reducing testing time. Johnson (1) identifies three methods for reducing test time. In the first method, more specimens are run simultaneously than are intended to fail. For example, Johnson points out that for a Weibull slope of 1.0, the median time to fail 10 out of 20 samples is significantly less than the median time required to fail 10 out of 10 samples. In fact, the first scenario will take 24 percent of the time it takes for the second. This is assuming that there are no replacements of failed specimens, all testers are the same, and all specimens are run simultaneously. Since the width of the confidence band is determined by the number of items failed and not the total number of specimens in a test (1), (2) the number failed is 10 in both cases. As a result, the only difference is that the 10 items having the lowest lives in a lot of 20 is plotted on a Weibull plot instead of all 10 specimens in a lot of 10 (1). Similar observations were made by Vlcek, Hendricks, and Zaretsky in (2).

Johnson (1) describes sequential analysis as a second method of deciding if an improvement in life has been realized at any time during the test series based upon the performance of the latest element in a sequential group of failures. The total number of specimens needed to fail is not known in advance. The investigator decides after each failure whether or not additional testing is required. In this manner, the bare minimum number of runs needed to demonstrate an improvement or worsening of life is conducted. A method similar to this has been used extensively by Zaretsky et al. (3). An estimate of the 50-percent life $\left(\boldsymbol{L}_{50}\right)$ is made and test bearings are then run on identical testers until this life is reached. As samples fail or are suspended at the $\boldsymbol{L}_{\mathbf{5 0}}$ life, they are removed, and new samples are mounted and evaluated to the estimated $\boldsymbol{L}_{50}$. In this manner, at least 50 percent of the samples are typically failed out of the entire available population. In some cases, the $\boldsymbol{L}_{\mathbf{5 0}}$ target may have to be adjusted as dictated by the number of failures encountered.

Sudden death testing is the third method of reducing testing time described by Johnson (1). The total accumulated test time is reduced by not running all specimens to failure. The total number of specimens to be evaluated $\boldsymbol{n}$ is divided into equal-sized subgroups according to the number of available experimental testers. Thus, there are $\boldsymbol{m}$ specimens in each equal-sized subgroup, and there are a total of $\boldsymbol{r}$ subgroups (Table 1(a)). The total number of specimens evaluated $\boldsymbol{n}$ equals $\boldsymbol{m}$ times $\boldsymbol{r}$.

The specimens in each subgroup are fatigue tested identically and simultaneously on different testers. The first subgroup of specimens is run until the first failure occurs. At this point, the surviving specimens are suspended and 
removed from testing. An equal set of new specimens numbering $\boldsymbol{m}$ samples is next tested until the first failure in that subpopulation. This process is repeated until one failure is generated for each of the subgroups. In the end, $\boldsymbol{r}$ failures are generated while $(\boldsymbol{m}-1) \times \boldsymbol{r}$ samples are suspended (Table 1(b)). Thus, the total accumulative test time is the time to fail $\boldsymbol{r}$ specimen times the number of samples concurrently tested $\boldsymbol{m}$, not the time for $\boldsymbol{n}$ failures. With correct analysis, reliability of the life predicted from $\boldsymbol{r}$ failures is assumed to be comparable to that obtained when failing the entire population. Some sudden death testing results are reported in (4)-(8). The issue remains as to whether life predictions from sudden death testing are equivalent to those obtained with sequentially failed data.

It is time-consuming and cost prohibitive to rigorously examine the advantages of sudden death testing in the physical world. However, sudden death testing can be investigated by the generation of virtual bearing sets for evaluation to an extent that might not be possible with physical testing. Vlcek, Hendricks, and Zaretsky (2) have shown that computer modeling of bearing life based upon Monte Carlo assignment of bearing component median ranks, and probabilistic characteristics based upon Lundberg and Palmgren (9) results in reasonable engineering predictions of bearing life that are relatively easy to determine. These predictions compared favorably to the rollingelement bearing data contained in (10), (11).

The generation of virtual bearing lives demonstrated by Vlcek, Hendricks, and Zaretsky (2) can be used to generate bearing sets, which will then be distributed into combinations of sudden death testing matrices. In view of the aforementioned, it is the objectives of the work reported herein to compare, 1 . the resultant bearing lives obtained using sudden death testing to the calculated bearing life, and 2. the cumulative test time and calendar time for sudden death testing relative to that for sequential testing methods.

Table 1.-An $\boldsymbol{n}$ specimen matrix of $\boldsymbol{r}$ subgroups and $\boldsymbol{m}$ samples evaluated (testers in use).

(a) Test matrix. (b) Failure matrix. (c) Test matrix example. (d) Failure matrix example.

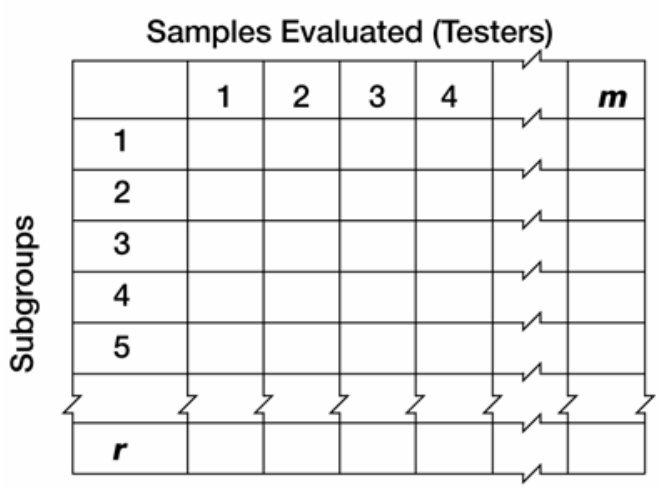

(a)

\begin{tabular}{|c|c|c|c|c|}
\hline \multicolumn{5}{|c|}{ Samples Evaluated (Testers) } \\
\hline & 1 & 2 & 3 & $4=\boldsymbol{m}$ \\
\hline 1 & & & & \\
\hline 2 & & & & \\
\hline 3 & & & & \\
\hline 4 & & & & \\
\hline 5 & & & & \\
\hline 6 & & & & \\
\hline 7 & & & & \\
\hline 8 & & & & \\
\hline $9=\boldsymbol{r}$ & & & & \\
\hline
\end{tabular}

(c)

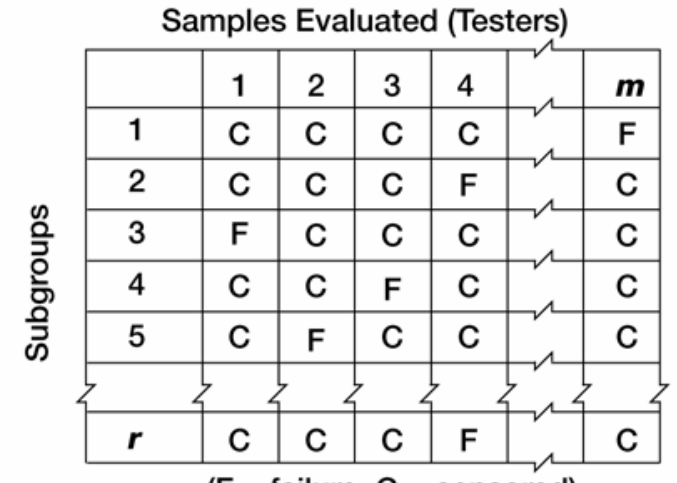

(b)

( $F=$ failure; $C=$ censored $)$

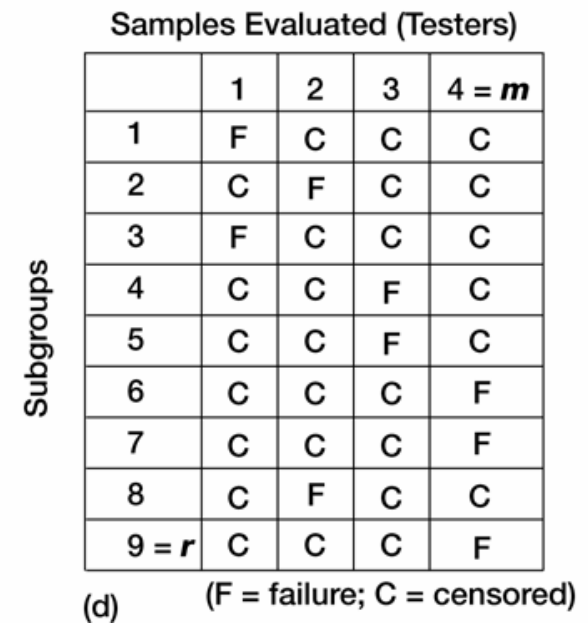




\section{PROCEDURE}

\section{Bearing Life Analysis}

Bearing life testing is expensive and time-consuming. As a result, it is desirable to predict by calculation the life of a bearing with reasonable engineering certainty. In probabilistic life models, the bearing physical characteristics, applied load, operating profile, and environment determine the probability of failure, assuming that the life is represented by a known probability function. W. Weibull (12)-(14) was the first to suggest a reasonable way to estimate material fracture strength with such a probability function. Based upon the work of Weibull (12)-(14) and G. Lundberg and A. Palmgren (9) in 1947 showed that the probability of survival $\boldsymbol{S}$ could be expressed as a power function of the orthogonal shear stress $\boldsymbol{t}_{\boldsymbol{o}}$, life $\boldsymbol{N}$, depth to the maximum orthogonal shear stress $\boldsymbol{Z}_{\boldsymbol{o}}$, and stressed volume $\boldsymbol{V}$. That is,

$$
\ln \frac{1}{S} \sim \frac{\tau_{o}^{c} N^{e}}{Z_{o}^{h}} V
$$

From Eq. [1], Lundberg and Palmgren (9) derived the following relation:

$$
\boldsymbol{L}_{10}=\left[\boldsymbol{C}_{\boldsymbol{D}} / \boldsymbol{P}_{\text {eq }}\right] \boldsymbol{p}
$$

where $\boldsymbol{C}_{\boldsymbol{D}}$, the basic dynamic load capacity, is defined as the load that a bearing can carry for one million innerrace revolutions with a 90-percent probability of survival, $\boldsymbol{P}_{\boldsymbol{e q}}$ is the equivalent bearing load, and $\boldsymbol{p}$ is the load life exponent.

Lundberg and Palmgren (9) first derived the relationship between individual component life and system life. A bearing is a system of multiple components each with a different life. As a result, the life of the system is different from the life of an individual component in the system. The system life can be expressed, to a first order, as

$$
\frac{1}{L_{10 s y s} e^{e}}=\frac{1}{L_{10 i r}{ }^{e}}+\frac{1}{L_{10 o r}{ }^{e}}
$$

where the life of the rolling element by inference is incorporated into the life of each raceway. In properly designed and operated rolling-elements bearings, fatigue of the cage or separator should not occur and, therefore, is not considered in determining bearing life and reliability.

The work of E.V. Zaretsky (15) builds upon the work of Lundberg and Palmgren (9) where using Zaretsky's rule (15)

For radially loaded ball and roller bearings, the life of the rolling element set is equal to or greater than the life of the outer race. Let the life of the rolling element set be equal to that of the outer race.

then with this assumption, Eq. [3] becomes

$$
\left[1 / L_{10}\right] e=\left[1 / L_{i r}\right] e+2\left[1 / L_{o r}\right] e
$$

where $\boldsymbol{L}_{\boldsymbol{r e}}=\boldsymbol{L}_{\text {or }}$

The life of a virtual bearing was calculated according to Lundberg and Palmgren (9) with a lubricant life factor from (15). The lives of the inner and outer races were recalculated together with the lives of the balls using Eq. [4].

\section{Bearing Type, Operating Conditions, and Calculated Lives}

The virtual bearings in this study were generated using physical bearing parameters. The bearings were a 6010-size (50-mm bore) deep-groove ball bearing. The bearing dimensions and operating conditions are summarized in Table 2. Operating conditions were assumed to be $10000 \mathrm{rpm}$ using an MIL-L-23699 (tetraester-based) lubricant at $135{ }^{\circ} \mathrm{C}$ $\left(275^{\circ} \mathrm{F}\right)$. The load applied to bearing was calculated to result in a maximum Hertz stress of $1.55 \mathrm{GPa}(225 \mathrm{ksi})$ on the inner race of the bearing. 
Table 2.-Bearing specifications, operating conditions, and calculated lives used in assembly and Monte Carlo sudden death testing.

\begin{tabular}{|c|c|c|c|c|}
\hline \multicolumn{2}{|c|}{ Bearing type } & \multicolumn{3}{|c|}{ Deep-groove ball bearing } \\
\hline \multicolumn{2}{|c|}{ Bore size, mm } & \multicolumn{3}{|c|}{50} \\
\hline \multirow{2}{*}{$\begin{array}{l}\text { Curvatures, } \\
\text { percent }\end{array}$} & Inner race & \multicolumn{3}{|c|}{52} \\
\hline & Outer race & \multicolumn{3}{|c|}{52} \\
\hline \multicolumn{2}{|c|}{ Ball diameter, mm (in.) } & \multicolumn{3}{|c|}{$87.3(11 / 32)$} \\
\hline \multicolumn{2}{|c|}{ Number of balls } & \multicolumn{3}{|c|}{14} \\
\hline \multicolumn{2}{|c|}{ Contact angle, deg } & \multicolumn{3}{|c|}{0} \\
\hline \multicolumn{2}{|c|}{ Load, N (lbs) } & \multicolumn{3}{|c|}{950 (215) radial } \\
\hline \multicolumn{2}{|c|}{$\begin{array}{l}\text { Maximum Hertz stress, } \\
\text { GPa (ksi) }\end{array}$} & \multicolumn{3}{|c|}{$1.55(255)$} \\
\hline \multicolumn{2}{|c|}{ Lubricant type } & \multicolumn{3}{|c|}{ MIL-L-23699 } \\
\hline \multicolumn{2}{|c|}{\begin{tabular}{l|l} 
Surface & Inner race
\end{tabular}} & \multicolumn{3}{|c|}{$7.62 \times 10^{-2}(3)$} \\
\hline \multirow{2}{*}{$\begin{array}{l}\text { Surface } \\
\text { finish, rms } \\
\mu \mathrm{m} \text { ( } \mu \text { in.) }\end{array}$} & Outer race & \multicolumn{3}{|c|}{$7.62 \times 10^{-2}(3)$} \\
\hline & Balls & \multicolumn{3}{|c|}{$2.54 \times 10^{-2}(1)$} \\
\hline \multicolumn{2}{|c|}{$\begin{array}{l}\text { Operating temperature, } \\
{ }^{\circ} \mathrm{C},\left({ }^{\circ} \mathrm{F}\right)\end{array}$} & \multicolumn{3}{|c|}{135 (275) } \\
\hline \multirow{2}{*}{$\begin{array}{l}\text { Lubricant } \\
\text { life factors }\end{array}$} & Inner race & \multicolumn{3}{|c|}{0.75} \\
\hline & Outer race & \multicolumn{3}{|c|}{1.05} \\
\hline \multirow[t]{5}{*}{ Life, hrs } & Component & $L_{10}$ & $L_{50}$ & $L_{\beta}$ \\
\hline & Inner race $^{a}$ & 9547 & 52123 & 72500 \\
\hline & Outer race $^{a}$ & 38188 & 208448 & 290000 \\
\hline & Ball $^{a}$ & 38118 & 208448 & 290000 \\
\hline & Bearing $^{b}$ & 6912 & 37729 & 47227 \\
\hline
\end{tabular}

${ }^{a}$ Life based on Zaretsky's rule and lubricant life factor (15).

${ }^{b}$ Life based on Lundberg-Palmgren equation (9) and lubricant life factor (15).

The lives of the bearing components and the bearing were calculated using a commercial bearing code, COBRA-EHL, incorporating the Lundberg-Palmgren (9) equations (Eqs. [1] and [2] and Zaretsky's rule, Eq. [4]). For purposes of the life analysis, all life factors with the exception of the lubricant life factor were assumed to be equal to one since interest was primarily in the qualitative results. A lubricant life factor, however, was used as a function of lubricant film parameter from (15) for these operating conditions since its effect on the resulting lives of the inner and outer races can be different. Following Lundberg and Palmgren (9), the Weibull slope $\boldsymbol{e}$ was assumed to equal 1.11 for each of the bearing components in this study. This results in a near-exponential distribution of the bearing failure data. The resultant bearing $\boldsymbol{L}_{\mathbf{1 0}}$ life was $6912 \mathrm{hr}$.

Lundberg and Palmgren (9) incorporated into their analysis a method and distribution function for statistically describing the fatigue life of materials developed by Weibull (12) referred to as the two-parameter Weibull distribution function.

$$
\ln \ln \frac{1}{S}=e \ln \left(\frac{L}{L_{\beta}}\right) ; 0<L<\infty ; 0<S<1
$$

The characteristic lives $\left(\boldsymbol{L}_{\beta}\right)$ calculated using Eq. [5] for the inner race, the balls, and the outer race were 72 490; 289 000; and 289000 hr, respectively. 


\section{Virtual bearing testing}

Whether the data is generated experimentally or analytically, the ultimate goal is to determine the life and characteristics of a larger population from a limited amount of data. Since exhaustive physical testing is economically prohibitive, and in some cases not physically possible, it is extremely desirable to mathematically model the life of a bearing. Probabilistic approaches are based upon the fact that material strength varies from sample to sample as a result of material inhomogeneities and manufacturing variability. The applied loads to a system are also variable as a result of operation loads, mission cycles, and environmental factors. As a result, component life is modeled as a statistical variable. If the applied load is known in terms of duty cycle together with the relevant bearing geometry and operating conditions, the probability of failure is determined assuming that the bearing life is represented by a known probability function.

The life of virtual bearings consisting of multiple components was determined using the method demonstrated in Ref. (2). It was assumed that each bearing was assembled from three separate bins of components, with one bin containing 1000 inner rings, one 1000 rolling element sets, and one 1000 outer rings. The median ranks of the individual components were assigned and then virtual bearing assemblies were created using a Monte Carlo technique. The corresponding life of the bearing components were determined using Eq. [5]. The weakest link theory was applied, that is it was assumed that the life of the shortest-lived component of the system was the life of the system. A linear curve fit of these system lives results in a Weibull plot. Weibull parameters from the plot and Eq. [5] can be used to determine lives at any percentage of survivability.

Vlcek, Hendricks, and Zaretsky (2) determined the $\boldsymbol{L}_{\mathbf{1 0}}$ maximum limit and $\boldsymbol{L}_{\mathbf{1 0}}$ minimum limit for the number of bearings failed using a Weibull-based Monte Carlo method. By fitting the-resultant lives for different sized populations of failed bearings, equations were determined for both of these limits:

$$
\begin{gathered}
\text { Max variation } \boldsymbol{L}_{\mathbf{1 0}} \text { life }=\text { calc } \boldsymbol{L}_{\mathbf{1 0}} \text { life }\left(1+6 \boldsymbol{n}^{-\mathbf{0 . 6}}\right) \\
\text { Min variation } \boldsymbol{L}_{\mathbf{1 0}} \text { life }=\text { calc } \boldsymbol{L}_{\mathbf{1 0}} \text { life }\left(1-1.5 \boldsymbol{n}^{-\mathbf{0 . 3 3}}\right) \text { where } \boldsymbol{r}>3 \\
\text { Min } \boldsymbol{L}_{\mathbf{1 0}} \text { life }=0 \text { where } \boldsymbol{r} \leq 3
\end{gathered}
$$

These curves compared favorably with the 90-percent confidence limits of Johnson (1) at a Weibull slope of 1.5 (2). Additionally, field bearing life data of Harris (10), (11) was compared to these limit curves, and most of the bearing lives fell within these bounds (2). The upper and lower limits are thus assumed to be reasonable bounds and are a function of only the number of bearings failed and the known characteristic life of the bearing. Equations [6a] to [6c] were determined from Monte Carlo simulation of testing all bearings to failure.

\section{Data Analysis}

There are multiple statistical methods for determining bearing life estimates from endurance data that for practical engineering purposes, give similar results. These methods differ significantly; however, in their level of complexity to apply and limitations to their application. For example, maximum likelihood estimates (MLE) of Weibull slope, characteristic life $\boldsymbol{L}_{\beta}$ (life at which 63.2 percent of the specimens have failed), and $\boldsymbol{L}_{\mathbf{1 0}}$ (life at which 10 percent of the specimens have failed) can be found from an iterative process (16). Confidence limits can be placed upon these values using published tables that are appropriate for a limited number of testing configurations (6), (7). In general, extensive Monte Carlo simulations are required to generate additional entries for the tables found in the open literature. The relative likelihood method can also be employed to estimate statistical intervals (16). Linear regression least-square fits of mean order numbers assigned to experimental lives also result in estimations of Weibull slope, $\boldsymbol{e}$, characteristic life, $\boldsymbol{L}_{\beta}$, and $\boldsymbol{L}_{\mathbf{1 0}}$ life when plotted on Weibull paper. Confidence limits can be placed upon these values using the method of Johnson (1). For its relative ease of use and engineering application with comparable reliability, we have selected the linear regression least-square-fit method over that of maximum likelihood estimations for use in this study.

\section{Sudden Death Testing Techniques}

In sudden death testing, the total number of specimens to be evaluated is divided into equal subgroups that can be evaluated simultaneously. The first subgroup of specimens is run simultaneously until the first failure occurs. The 


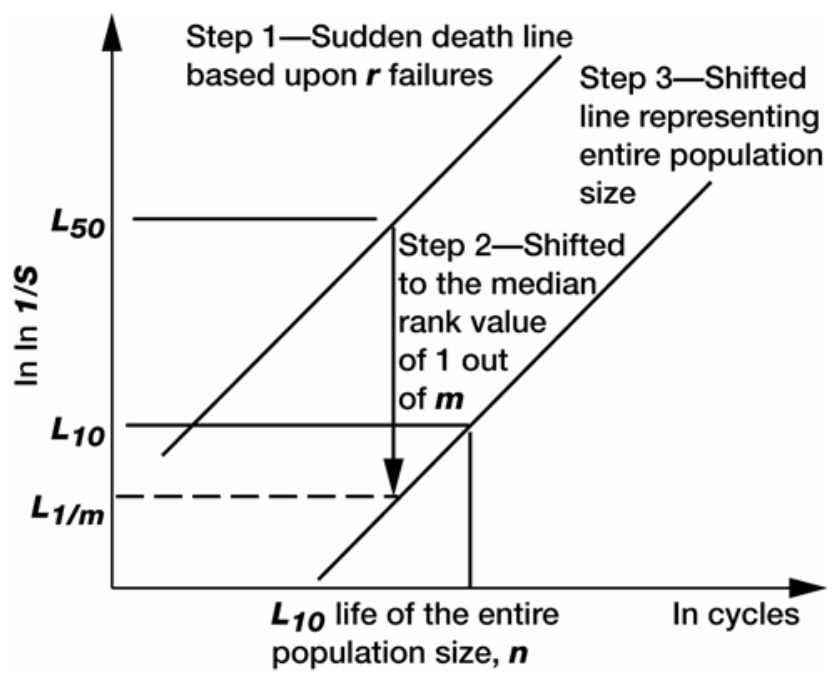

Figure 1.-Schematic of generic Weibull plot of the sudden death line shifted to total population line (Ref. (1)). surviving tests for that subgroup are terminated (i.e., suspended), and new test specimens are mounted in the testers. This process is repeated until all of the subgroups of test specimens in the population have been screened.

In this study, the technique developed by Vlcek, Hendricks, and Zaretsky (2) was used to generate virtual bearing sets that were then analyzed as if they were sudden death tested. Total populations with 36 , 72 , and 144 deep-groove bearings were generated. The populations were then sequentially broken into subgroups representing all possible combinations of sudden death test series of $(\boldsymbol{m} \times \boldsymbol{r})$, where $\boldsymbol{m}$ was the number of bearing testers used simultaneously and $\boldsymbol{r}$ was the number of sets of $\boldsymbol{m}$ bearings necessary to achieve the total number of bearings $\boldsymbol{n}$ in the total population. The total number of bearings $\boldsymbol{n}$ equals $\boldsymbol{m}$ times $\boldsymbol{r}$. For example, if 36 bearings were to be evaluated, and there were 4 bearing fatigue testers available, the value of $\boldsymbol{m}$ would be 4 while the value of $\boldsymbol{r}$ would be 9; whereby $\boldsymbol{n}$ equals 36[( $\boldsymbol{m}=4) \times(\boldsymbol{r}=9)]$ (Table 1(c)). For this example, the first four bearings were run simultaneously until the first failure occurred. The three surviving tests were suspended, and four new bearings were mounted. This process was repeated until 9 failures occurred, 1 from each of the sets of 4 , with $(\boldsymbol{m}-1) \times \boldsymbol{r}$ or 27 suspensions (Table $1(\mathrm{~d})$ ).

These nine failures and their corresponding median ranks, one for each subgroup of size $\boldsymbol{m}$, were then plotted on a Weibull plot. This sudden death line (SDL) represents the distribution of first failures in each subgroup. The SDL of each series was next shifted on its respective Weibull plot so that the curve represented the failures of the total population, not just that of one out of $\boldsymbol{r}$ bearings.

Various methods exist for shifting the SDL line and finding the life of a total population $\boldsymbol{n}$ based upon sudden death testing data where only $\boldsymbol{r}$ failures are considered. The slope and characteristic life of the subpopulation generated during sudden death testing can be found from maximum likelihood estimators of Cohen (17) that are obtained from an iterative process. This life for $\boldsymbol{r}$ samples must be corrected to represent the life of the original population containing $\boldsymbol{n}$ samples. One way to achieve this, as reported by McCool (6), (7) is to multiply the subpopulation life estimator by the number of samples $(\boldsymbol{m})$ in each equally sized subpopulation raised to the inverse of the slope estimator. Confidence limits can be placed upon these values for a limited number of cases provided in tables in the open literature or by extensive Monte Carlo simulations (6), (7). Houpert (4) also proposes a technique for determining the life of a larger population based upon a subpopulation determined from sudden death testing, but a comparison to our work is beyond the scope of this paper.

For its simplicity of application and relative engineering reliability, we prefer a technique presented by Johnson (1) for shifting the SDL so that the life and characteristics of the larger bearing population (n) can be projected. Figure 1 is a generic Weibull plot that accompanies the following steps and includes many of the elements mentioned:

Step 1-Plotting the subgroup of $\boldsymbol{r}$ failures on Weibull paper. To plot the failures, median ranks are assigned to the sequentially ordered lives. Median ranks were defined using

$$
\text { Median rank }=(\boldsymbol{j}-0.3) /(\boldsymbol{r}+0.4)
$$

where $\boldsymbol{j}=1,2,3, \ldots \boldsymbol{r}$. For sudden death testing, the number of subsets $\boldsymbol{r}$ equals the number tested to failure. A discussion and comparison of median rank definitions are available in (4) and (18). The median ranks along with their corresponding lives are next plotted on Weibull paper. The locus of points is fitted with a linear curve. From the Weibull plot, the Weibull slope, $\boldsymbol{L}_{\mathbf{1 0}}$ life, $\boldsymbol{L}_{\mathbf{5 0}}$ life, and characteristic life, $\boldsymbol{L}_{\beta}$, are determined. This SDL represents the distribution of first failures at the median rank for one failure out of the number of samples $(\boldsymbol{m})$ in each of the subgroups. 
Step 2-Determining by how much the SDL must be shifted to accurately estimate the $\boldsymbol{L}_{10}$ life for the entire population. The median rank (Eq. [7a]) must be determined for the first failure out of the number of bearings simultaneously evaluated $(\boldsymbol{m})$. In the above example, for a $[(\boldsymbol{m}=4) \times(\boldsymbol{r}=9)]$ test, the four simultaneous testers are stopped after the first test failure occurs, thus the mean order number $\boldsymbol{j}$ equals 1 and the subgroup size $\boldsymbol{m}$ equals 4 where it is assumed that in Eq. [7a], $\boldsymbol{m}$ equals $\boldsymbol{r}$. The median rank for one out of four, found using Eq. [7b], is 0.1591. This is the value to which the SDL must be shifted (Figure 1). In general

$$
\text { First failure median rank }(\text { FFMR })=(1-0.3) /(\boldsymbol{m}+0.4)
$$

Step 3-Constructing the total population line (TPL) by shifting the SDL. At the $\boldsymbol{L}_{50}$ intersection of the SDL, a vertical line is drawn down to the median rank value determined in step 2 . Through this point, a line is drawn parallel to the SDL created in step 1 . The slopes of both lines are assumed to be equal. Figure 1 is a generic Weibull plot of the SDL and the shifted TPL representative of this technique.

Step 4-Determining lives from the shifted TPL. The Weibull slope and lives are read directly from the TPL generated in step 3. Table 3 contains the Weibull slope, $\boldsymbol{L}_{\mathbf{1 0}}$ life, $\boldsymbol{L}_{\mathbf{5 0}}$ life, and characteristic life, $\boldsymbol{L}_{\beta}$, for a typical $[(\boldsymbol{m}=4) \times(\boldsymbol{r}=9)]$ sudden death test of a virtual deep-groove bearing. The values obtained from the SDL and the shifted TPL are provided.

Table 3.-Comparison between lives obtained from Monte Carlo sudden death testing and that adjusted for total population. Number of failures, 9; number of bearings tested, 36; number of test rigs, 4; assumed

Weibull slope, 1.11; resultant Weibull slope, 1.033; bearing size and type, $50-\mathrm{mm}$ bore deep-groove ball bearing.

\begin{tabular}{|l|c|c|c|c|}
\hline \multirow{2}{*}{$\begin{array}{l}\text { Bearing } \\
\text { population size }\end{array}$} & \multicolumn{3}{|c|}{ Bearing life, hrs } & Weibull \\
\cline { 2 - 5 } & $\boldsymbol{L}_{\mathbf{1 0}}$ & $\boldsymbol{L}_{\mathbf{5 0}}$ & $\boldsymbol{L}_{\boldsymbol{\beta}}$ & slope, $\boldsymbol{e}$ \\
\hline $\begin{array}{l}\text { Sudden death for } \\
\text { 9 failures }\end{array}$ & 2354 & 14569 & 20772 & 1.033 \\
\hline $\begin{array}{l}\text { Adjusted for } \\
\text { total population } \\
\text { from sudden } \\
\text { death }\end{array}$ & 9003 & 55729 & 79453 & 1.033 \\
\hline $\begin{array}{l}\text { Calculated } \\
\text { (actual) for total } \\
\text { population }\end{array}$ & 6912 & 37729 & 47729 & 1.11 \\
\hline
\end{tabular}

${ }^{a}$ Life based on Zaretsky's rule and lubricant life factor (15).

This process was repeated for each of the 33 combinations reported in Table 4. For each sudden death test combination, 10 different sets of lives were generated and their respective SDL determined. The SDLs were shifted appropriately and the $\boldsymbol{L}_{\mathbf{1 0}}$ lives determined from the TPL. The variation in the maximum and minimum $\boldsymbol{L}_{\mathbf{1 0}}$ life with respect to the calculated $\boldsymbol{L}_{\mathbf{1 0}}$ life and the maximum and minimum Weibull slopes for each of the 10 trial sets are reported in Table 4.

\section{RESULTS AND DISCUSSIONS}

Experimental testing will never be eliminated. Where appropriate and economical, physical testing is the method of choice. Sudden death testing techniques have been purported to have the potential to reduce test time and associated costs. An outstanding issue regarding sudden death testing is whether testing a large population but failing only a subset of specimens tested has advantages as compared to testing the entire bearing population to failure. It is not possible to examine this issue by physical testing. Because physical testing is limited and/or cost prohibitive, a Monte Carlo simulation based upon a known Weibull distribution has been demonstrated as a means of obtaining reasonable design limits (2). Merging these techniques has the potential to generate insightful data for test runs that might be impractical or impossible to otherwise run. 
Some of the test combinations and total number of virtual bearings evaluated in this study are impractical to evaluate from a physical sense. For example, one would probably not run a total of 144 bearings using only 2 testers. The results of such extremes, however, are included for completeness. The table entries (Table 4) corresponding to those testing combinations that are of "engineering application interest" are presented in bold script. Comparison of the Monte Carlo generated results from this study to upper and lower limits previously correlated to experimental data in (2) provides confidence in the results of the sudden death testing technique.

Table 4.- Summary of minimum and maximum variation from calculated $\boldsymbol{L}_{\mathbf{1 0}}$ life and Weibull slope from Monte Carlo simulation of assembly of 50-mm bore deep-groove ball bearings evaluated in 33 different sudden death test configurations comprising 36, 72, and 144 bearings.

\begin{tabular}{|c|c|c|c|c|c|}
\hline \multicolumn{6}{|c|}{ (a) 36 bearings, 8 configurations } \\
\hline \multirow{2}{*}{$\begin{array}{l}\text { No. of } \\
\text { simultaneously } \\
\text { operated testers }\end{array}$} & \multirow[t]{2}{*}{ No. of failures } & \multicolumn{2}{|c|}{$\begin{array}{c}\text { Variation from calculated } \boldsymbol{L}_{\mathbf{1 0}} \text { life, } \\
\text { percent }^{a}\end{array}$} & \multicolumn{2}{|c|}{ Variation in Weibull slope, $\boldsymbol{e}^{b}$} \\
\hline & & Minimum $^{c}$ & Maximum $^{c}$ & Minimum $^{c}$ & Maximum $^{c}$ \\
\hline 18 & 2 & -89 & 228 & 0.48 & 11.93 \\
\hline 12 & 3 & -92 & 303 & 0.32 & 3.02 \\
\hline 9 & 4 & -39 & 83 & 0.92 & 2.43 \\
\hline 6 & 6 & -37 & 53 & 0.57 & 2.43 \\
\hline 4 & 9 & -41 & 120 & 0.69 & 1.49 \\
\hline 3 & 12 & -55 & 86 & 0.73 & 1.54 \\
\hline 2 & 18 & -47 & 83 & 0.75 & 1.50 \\
\hline 1 & 36 & -58 & 67 & 0.83 & 1.21 \\
\hline \multicolumn{6}{|c|}{ (b) 72 bearings, 11 configurations } \\
\hline 36 & 2 & -88 & 886 & 0.39 & 6.02 \\
\hline 24 & 3 & -65 & 192 & 0.73 & 5.58 \\
\hline 18 & 4 & -51 & 93 & 0.54 & 1.49 \\
\hline 12 & 6 & -57 & 84 & 0.70 & 1.42 \\
\hline 9 & 8 & -10 & 61 & 0.70 & 1.78 \\
\hline 8 & 9 & -32 & 58 & 0.86 & 1.30 \\
\hline 6 & 12 & -26 & 33 & 0.78 & 1.64 \\
\hline 4 & 18 & -36 & 43 & 0.72 & 1.28 \\
\hline 3 & 24 & -68 & 116 & 0.75 & 1.52 \\
\hline 2 & 36 & -33 & 68 & 0.99 & 1.32 \\
\hline 1 & 72 & -32 & 51 & 0.98 & 1.26 \\
\hline \multicolumn{6}{|c|}{ (c) 144 bearings, 14 configurations } \\
\hline 72 & 2 & -89 & 55 & 1.26 & 9.03 \\
\hline 48 & 3 & -81 & 346 & 0.58 & 3.70 \\
\hline 36 & 4 & -48 & 330 & 0.61 & 1.21 \\
\hline 25 & 6 & -57 & 94 & 0.84 & 2.63 \\
\hline 18 & 8 & -42 & 67 & 0.82 & 2.61 \\
\hline 16 & 9 & -47 & 170 & 0.84 & 1.73 \\
\hline 12 & 12 & -26 & 66 & 0.88 & 1.67 \\
\hline 9 & 16 & -25 & 23 & 0.91 & 1.35 \\
\hline 8 & 18 & -33 & 50 & 0.78 & 1.61 \\
\hline $\begin{array}{l}6 \\
4\end{array}$ & 24 & -30 & 55 & 0.80 & 1.55 \\
\hline $\begin{array}{l}4 \\
3\end{array}$ & 36 & -24 & 39 & 0.90 & 1.25 \\
\hline $\begin{array}{l}3 \\
2\end{array}$ & 48 & -18 & 43 & 0.91 & 1.30 \\
\hline 2 & 72 & -34 & 25 & 0.93 & 1.31 \\
\hline$I$ & 144 & -16 & 23 & 0.99 & 1.25 \\
\hline
\end{tabular}

${ }^{a}$ Based upon calculated $\boldsymbol{L}_{\mathbf{1 0}}$ life of 6912 hours (from Table 1).

${ }^{b}$ Compare to assumed Weibull slope of 1.11 .

${ }^{c}$ Maximum and minimum values of life do not necessarily correlate with maximum and minimum values of Weibull slope. 


\section{Endurance Life Variation}

For each set of 10 trials for the 33 sudden death test combinations of 6010-size (50-mm bore) deep-groove bearings evaluated, the maximum and minimum $\boldsymbol{L}_{\mathbf{1 0}}$ life was determined and compared to the calculated $\boldsymbol{L}_{\mathbf{1 0}}$ life of $6912 \mathrm{hr}$. The maximum and minimum values of the $\boldsymbol{L}_{\mathbf{1 0}}$ lives as a percent of the calculated $\boldsymbol{L}_{\mathbf{1 0}}$ life for each combination $(\boldsymbol{m} \times \boldsymbol{r})$ of sudden death bearing tests with $\boldsymbol{r}$ bearing failures was determined as follows:

$$
\text { Max variation from calc } \begin{aligned}
\boldsymbol{L}_{\mathbf{1 0}} \text { life } & =\frac{\max \boldsymbol{L}_{\mathbf{1 0}}-\operatorname{calc} \boldsymbol{L}_{\mathbf{1 0}}}{\text { calc } \boldsymbol{L}_{\mathbf{1 0}}} \\
& \times 100 \text { percent }
\end{aligned}
$$

$$
\text { Min variation from calc } \boldsymbol{L}_{\mathbf{1 0}} \text { life }=\underline{\min } \underline{\boldsymbol{L}_{\mathbf{1 0}}} \frac{- \text { calc } \boldsymbol{L}_{\mathbf{1 0}}}{\text { calc } \boldsymbol{L}_{\mathbf{1 0}}} \times 100 \text { percent }
$$

These variations are reported in Table 4 for each of the 33 combination of sudden death tests evaluated.

The maximum and minimum $\boldsymbol{L}_{\mathbf{1 0}}$ life from 10 trials of each of the 33 sudden death test configurations studied are plotted in Figure 2. Additionally, the $\boldsymbol{L}_{\mathbf{1 0}}$ life bounding limits from (2) are shown. There were 9 possible combinations of sudden death test configurations for 36 bearings (Figure 2(a)), 11 possible combinations of test configurations for 72 (Figure 2(b)), and 14 possible combinations of test configurations for 144 (Figure 2(c)) deepgroove ball bearings. In 29 out of the 33 possible test combinations, the $\boldsymbol{L}_{\mathbf{1 0}}$ values fell within these upper and lower bounds established in (2). In three of the cases, the maximum $\boldsymbol{L}_{\mathbf{1 0}}$ life value exceeded the upper bound. In all 32 cases the minimum $\boldsymbol{L}_{\mathbf{1 0}}$ life value fell on or above the minimum $\boldsymbol{L}_{\mathbf{1 0}}$ life bound. In only one case did the minimum $\boldsymbol{L}_{\mathbf{1 0}}$ life fall below the lower bound.

The percent variation of the maximum predicted $\boldsymbol{L}_{\mathbf{1 0}}$ life from that of the calculated life is re-plotted in the bar chart of Figure 3(a). The minimum values are shown in Figure 3(b). The variations in life are grouped according to the total number of bearings tested $[\boldsymbol{n}=\{36,72,144\}]$ and as a function of the number of bearings failed $[\boldsymbol{r}=\{2,3,4,6,9,12,18,36\}]$ or the number of bearing testers simultaneously used. Some variations or scatter in the range between the percent variations obtained for different total numbers of bearings tested at the same number of failures are observed. For sudden death testing the percent variation in the resultant $\boldsymbol{L}_{\mathbf{1 0}}$ life from that calculated is independent of the number of bearings tested and dependent only on the number of bearings failed.

A curve fit of the variation in $\boldsymbol{L}_{\mathbf{1 0}}$ life as a function of the number of bearings failed for the sudden death failed Monte Carlo data results in the following relation:

$$
\begin{aligned}
& \text { Max variation } \boldsymbol{L}_{\mathbf{1 0}} \text { life sudden death }=\text { calc } \boldsymbol{L}_{\mathbf{1 0}} \text { life }\left(1+6 \boldsymbol{r}^{-0.6}\right) \\
& \text { Min variation } \boldsymbol{L}_{\mathbf{1 0}} \text { life sudden death }=\text { calc } \boldsymbol{L}_{\mathbf{1 0}} \text { life }\left(1-1.2 \boldsymbol{r}^{-0.33}\right)
\end{aligned}
$$

where $\boldsymbol{r}$ equals the total number of bearings failed in sudden death testing. Equations [6a] and [9a] for sequential testing and sudden death testing, respectively, are equal. The minimum values obtained for sequential testing (Eq. [6b]) is 20 percentage points less than that obtained for sudden death testing (Eq. [9b]). For most engineering applications, this difference is negligible. Accordingly, from an engineering point of view, these two curve fits are equivalent. Since Eq. [9b] is a curve-fit of minimum $\boldsymbol{L}_{\mathbf{1 0}}$ lives from populations of 36, 72, and 144 bearings failed, and this in turn is in agreement with the curve-fit for sequentially generated failures (Eq. [6b]), it can be concluded that the percent variation in life is a function of the number of failed bearings and not the total number of bearings evaluated. This observation is consistent with those of Vlcek, Hendricks, and Zaretsky (2) and Johnson (1). It can also be concluded that the determination of the life is independent of the method of obtaining the data, whether it is sequential or sudden death testing.

\section{Weibull Slope Variation}

Lundberg and Palmgren (9) assumed the value of the Weibull slope $\boldsymbol{e}$ in Eq. [5] to be 1.11. Experience has shown that most rolling-element bearing life data exhibit Weibull slopes between 1 and 2. For this analysis, a Weibull slope of 1.11 was assumed for all of the components for each bearing. This should theoretically result in a Weibull slope of 1.11 for the bearing system. 

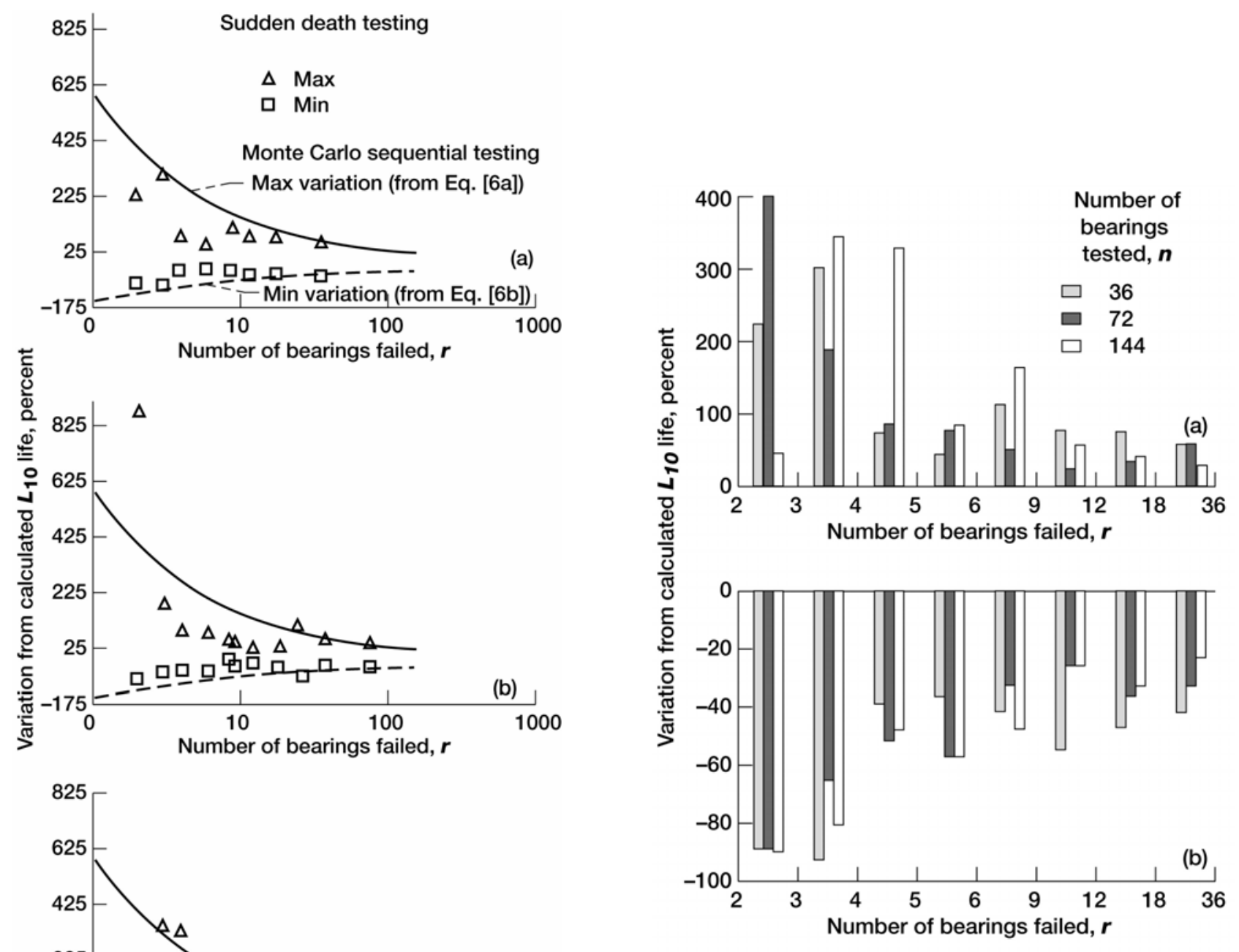

Figure 3.-Maximum and minimum variation of $L_{\mathbf{1 0}}$ lives as percent of calculated $\boldsymbol{L}_{\mathbf{1 0}}$ life as function of number of bearings tested, $\boldsymbol{n}$, and number of bearings failed, $\boldsymbol{r}$, for sudden death testing of $50-\mathrm{mm}$ bore deep-groove ball bearings. (a) Maximum variation. (b) Minimum variation.

Figure 2.-Maximum and minimum variation of $\boldsymbol{L}_{\mathbf{1 0}}$ lives as percent of calculated $\boldsymbol{L}_{\mathbf{1 0}}$ life for groups of sudden death tested bearings compared to maximum and minimum variation of $\boldsymbol{L}_{\mathbf{1 0}}$ life from sequential testing for $50-\mathrm{mm}$ bore deep-groove ball bearings. (a) Number of bearings tested, $\boldsymbol{n}, 36$. (b) Number of bearings tested, $\boldsymbol{n}, 72$. (c) Number of bearings tested, $\boldsymbol{n}, 144$. 

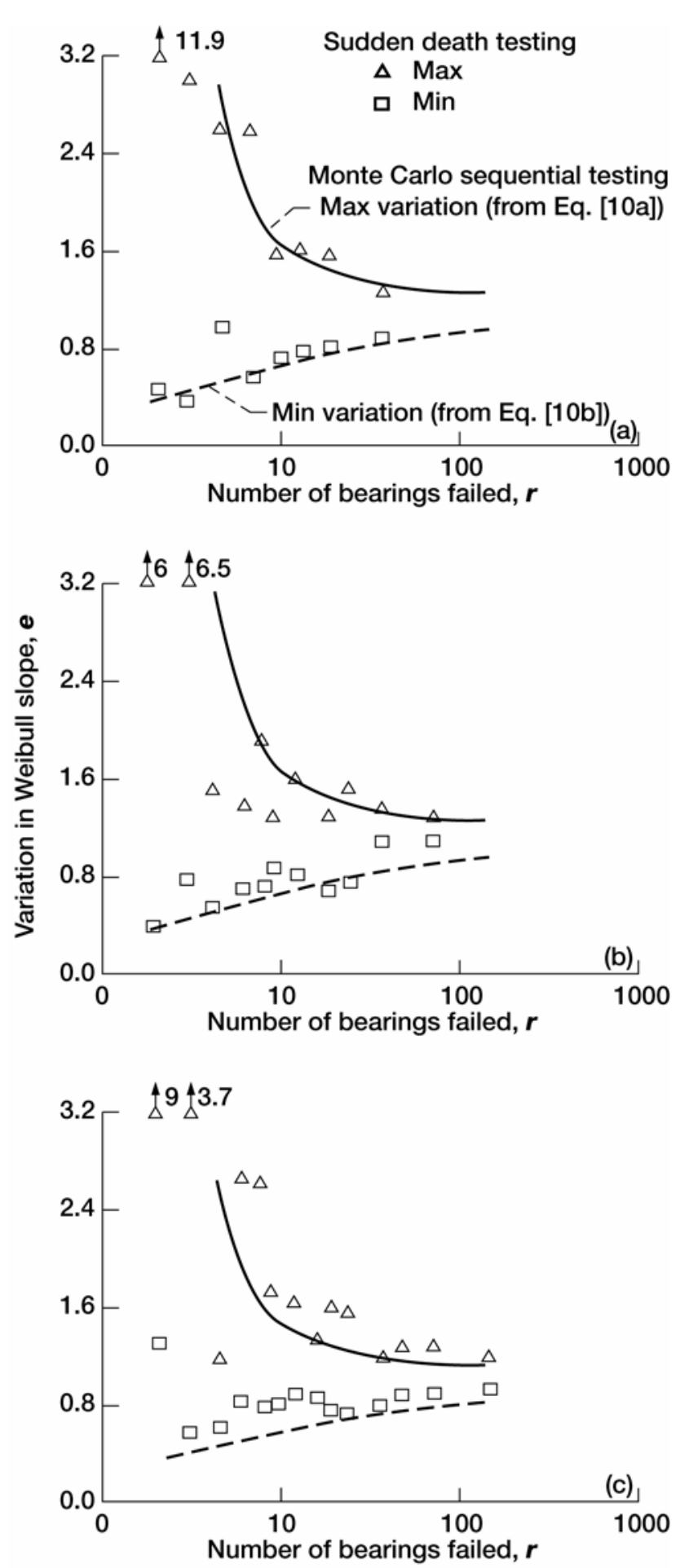

Figure 4.-Variation of Weibull slope $\boldsymbol{e}$ for Monte Carlo sudden death testing for each group of 10 bearing trials comprising $\boldsymbol{n}$ 50-mm bore deep-groove ball bearings each compared to extremes of Weibull slope from Monte Carlo sequential testing. (a) Number of bearings tested, $\boldsymbol{n}, 36$. (b) Number of bearings tested, $\boldsymbol{n}, 72$. (c) Number of bearings tested, $\boldsymbol{n}, 144$.
The results of the extremes in the Weibull slopes for each group of the 10 bearing trials of $\boldsymbol{r}$ bearing failures are summarized in Table 4 . The maximum and minimum bearing lives are not necessarily associated with the same trials as the maximum and minimum values of the Weibull slopes.

Vlcek, Hendricks, and Zaretsky (2) show that the relation between the number of bearings that failed and the limits of the Weibull slope is as follows:

$$
\begin{gathered}
\text { Max Weibull slope }=1.2+5(\ln r)^{-3} \\
\text { Min Weibull slope }=1.11-0.95 r^{-0.33}
\end{gathered}
$$

In this study, the Weibull slope extremes from 10 trials of 33 combinations of sudden death testing are compared to the upper and lower limit bounds from (2). Figure 4 contains the Weibull slope $\boldsymbol{e}$ limits as well as the maximum and minimum Weibull slope $\boldsymbol{e}$ from 10 trials of each of the 33 sudden death test configurations studied. There were 9 possible combinations of test configurations for 36 bearings (Figure 4(a)), 11 possible combinations of test configurations for 72 (Figure 4(b)), and 14 possible combinations of test configurations for 144 (Figure 4(c)) deep-groove bearings. In 21 out of the 33 possible test combinations, the extreme values of the Weibull slope fell within in these upper and lower bounds. In 11 of the cases, the maximum Weibull slope exceeded the upper bound. Of the 33 minimum values generated, in only one case did the minimum Weibull slope fall below the lower bound. Most of the significant upper bound violations occurred for 30 or less failed bearings.

\section{Comparison of Bearing Test Time}

An examination of the data summarized in Table 5 reveals that both in actual bearing test time and in calendar time, sudden death testing requires less time than sequential testing to failure an entire population of $\boldsymbol{n}$ bearings using the same number of testers simultaneously. However, where the number of bearings failed $\boldsymbol{r}$ is less than $\boldsymbol{n}$, the reliability of the results, as measured by the extent of data variation, is poor as compared to testing the entire population $\boldsymbol{n}$ to failure. It was concluded that whether employing sudden death testing or sequential testing, the reliability of the data is a function of the number of bearings failed $\boldsymbol{r}$ and not the number of bearings tested $\boldsymbol{n}$. If it is required to fail $\boldsymbol{r}$ number of specimens in order to obtain $\boldsymbol{L}_{\mathbf{1 0}}$ estimates of desired reliability, the question remains whether it is advantageous in terms of testing or calendar time to fail (a) all specimens using sequential testing, (b) $\boldsymbol{r}$ of $\boldsymbol{n}$ specimens using $\boldsymbol{m}$ testers, or (c) some other variation of these schemes. 
The Monte Carlo sudden death testing results summarized in Tables 4 and 5 incorporated up to 144 testers operating simultaneously. It is recognized by us that most test facilities generally will have less than nine testers of a particular kind and most likely not more than two to eight testers operating simultaneously. Since the reliability of the data is dependent on the number of failures generated $\boldsymbol{r}$, the issue becomes what is the most time- and costefficient way to utilize these assets.

Table 5.-Effect of sudden death testing and sequential testing on bearing test time and calendar time for test completion of 50-mm bore deep-groove ball bearings evaluated in 33 different sudden death configurations comprising 36, 72, and 144 bearings.

\begin{tabular}{|c|c|c|c|c|c|c|}
\hline \multirow{2}{*}{$\begin{array}{l}\text { No. of } \\
\text { simultaneously } \\
\text { operated } \\
\text { testers }\end{array}$} & \multicolumn{3}{|c|}{ Sudden death testing } & \multicolumn{3}{|c|}{ Sequential testing } \\
\hline & $\begin{array}{l}\text { Failure } \\
\text { index }^{a}\end{array}$ & $\begin{array}{l}\text { Bearing test } \\
\text { time, hrs. }{ }^{b}\end{array}$ & $\begin{array}{l}\text { Calendar } \\
\text { time, hrs. }{ }^{c}\end{array}$ & $\begin{array}{l}\text { Failure } \\
\text { index }^{a}\end{array}$ & $\begin{array}{l}\text { Bearing test } \\
\text { time, hrs. }{ }^{b}\end{array}$ & $\begin{array}{l}\text { Calendar } \\
\text { time, hrs. }{ }^{c}\end{array}$ \\
\hline \multicolumn{7}{|c|}{ (a) 36 bearings, 8 configurations } \\
\hline 18 & $2 / 36$ & $125.1 \times 10^{3}$ & $7.0 \times 10^{3}$ & $36 / 36$ & $1813.3 \times 10^{3}$ & $100.7 \times 10^{3}$ \\
\hline 12 & $3 / 36$ & 243.8 & 20.3 & & & 151.1 \\
\hline 9 & $4 / 36$ & 244.6 & 27.2 & & & 201.5 \\
\hline 6 & $6 / 36$ & 363.6 & 60.6 & & & 302.2 \\
\hline 4 & 9/36 & 516.7 & 129.2 & & & 453.3 \\
\hline 3 & $12 / 36$ & 580.4 & 226.8 & & & 604.4 \\
\hline 2 & $18 / 36$ & $882.0 \times 10^{3}$ & $441.0 \times 10^{3}$ & $\downarrow$ & $\downarrow$ & $906.6 \downarrow$ \\
\hline 1 & -- & -- & -- & $36 / 36$ & $1813.3 \times 10^{3}$ & $1813.3 \times 10^{3}$ \\
\hline \multicolumn{7}{|c|}{ (b) 72 bearings, 11 configurations } \\
\hline 32 & $2 / 72$ & $93.4 \times 10^{3}$ & $2.6 \times 10^{3}$ & $72 / 72$ & $3640.2 \times 10^{3}$ & $101.1 \times 10^{3}$ \\
\hline 24 & $3 / 72$ & 246.2 & 10.3 & & & 151.7 \\
\hline 18 & $4 / 72$ & 257.3 & 14.3 & & & 202.2 \\
\hline 12 & $6 / 72$ & 393.5 & 32.8 & & & 303.3 \\
\hline 9 & $8 / 72$ & 484.9 & 53.9 & & & 404.5 \\
\hline 8 & 9/72 & 535.6 & 67.0 & & & 455.0 \\
\hline 6 & $12 / 72$ & 712.1 & 118.7 & & & 606.7 \\
\hline 4 & $18 / 72$ & 1170.0 & 292.5 & & & 910.0 \\
\hline 3 & $24 / 72$ & 1273.0 & 424.3 & & & 1213.4 \\
\hline 2 & $36 / 72$ & $1954.9 \times 10^{3}$ & $977.5 \times 10^{3}$ & $\downarrow$ & $\downarrow$ & 1820.1 \\
\hline 1 & -- & -- & -- & $72 / 72$ & $3640.2 \times 10^{3}$ & $3640.2 \times 10^{3}$ \\
\hline \multicolumn{7}{|c|}{ (c) 144 bearings, 14 configurations } \\
\hline 72 & $2 / 144$ & $157.5 \times 10^{3}$ & $2.2 \times 10^{3}$ & $144 / 144$ & $7129.9 \times 10^{3}$ & $99.0 \times 10^{3}$ \\
\hline 48 & $3 / 144$ & 271.2 & 5.7 & & & 148.5 \\
\hline 36 & $4 / 144$ & 348.1 & 9.7 & & & 198.0 \\
\hline 25 & 6/144 & 458.7 & 18.3 & & & 285.1 \\
\hline 18 & $8 / 144$ & 590.6 & 32.8 & & & 396.0 \\
\hline 16 & 9/144 & 633.5 & 39.6 & & & 445.5 \\
\hline 12 & $12 / 144$ & 828.9 & 69.1 & & & 594.0 \\
\hline 9 & $16 / 144$ & 985.9 & 109.5 & & & 792.0 \\
\hline 8 & $18 / 144$ & 1047.8 & 131.0 & & & 891.0 \\
\hline 6 & $24 / 144$ & 1463.4 & 243.9 & & & 1188.0 \\
\hline 4 & $36 / 144$ & 2189.7 & 547.4 & & & 1782.0 \\
\hline 3 & $48 / 144$ & 2652.9 & $884.3 \downarrow$ & & & 2376.0 \\
\hline 2 & $72 / 144$ & $4008.0 \times 10^{3}$ & $2004.0 \times 10^{3}$ & $\downarrow$ & $\downarrow$ & $3584.0 \downarrow$ \\
\hline 1 & -- & -- & -- & $144 / 144$ & $7129.9 \times 10^{3}$ & $7127.9 \times 10^{3}$ \\
\hline
\end{tabular}

${ }^{a}$ Number of bearings failed out of number of bearings tested.

${ }^{b}$ Total bearing test time for all bearings tested.

${ }^{c}$ Total calendar time to test all the bearing based upon $100 \%$ tester utilization. 


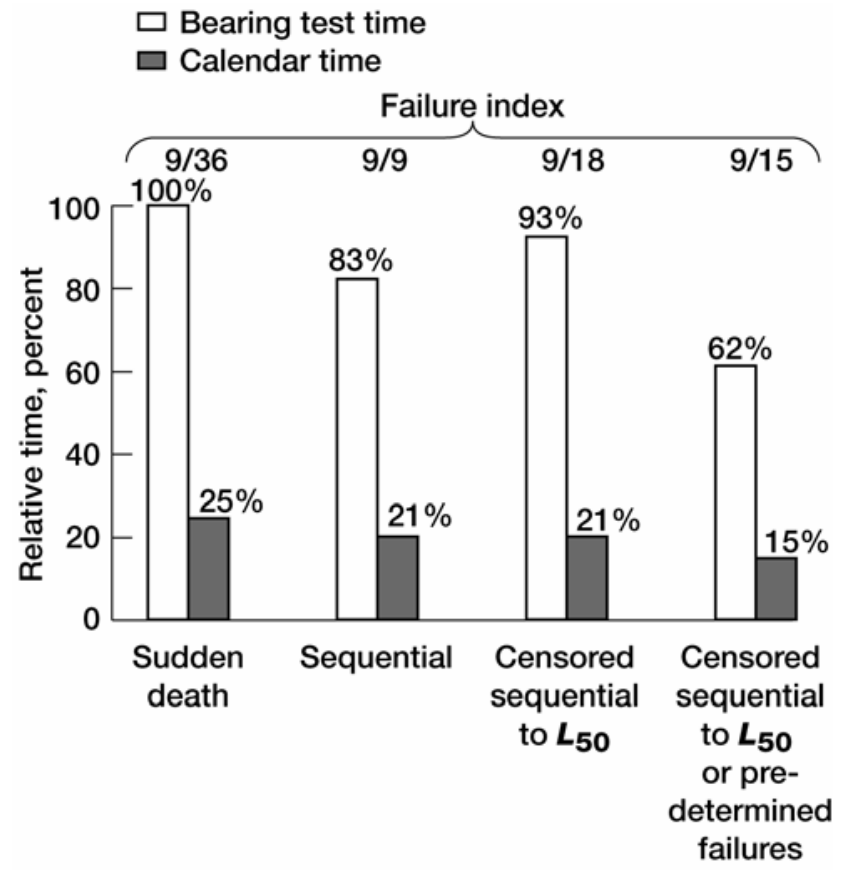

Figure 5.-Comparison of bearing test and calendar time for various testing methods using four testers simultaneously.
In the introduction to this paper, we discussed different testing techniques. Besides sudden death testing and sequential testing the entire population to failure using multiple testers, we also discussed (a) testing bearings to failure or the $\boldsymbol{L}_{50}$ life, whichever comes first and (b) testing to a predetermined number of failures $\boldsymbol{r}$ and then terminate all remaining tests. A combination of these test methods would be to sequentially test to failure or the $\boldsymbol{L}_{50}$ life, whichever comes first, and then terminate all testing when the predetermined number of failures $\boldsymbol{r}$ is achieved.

For a predetermined number of failures $\boldsymbol{r}$, the test method chosen dictates the number of bearings $\boldsymbol{n}$ to be tested. Where sequential testing to a predetermined number of failures $\boldsymbol{r}$, the number of bearings required $\boldsymbol{n}$ equal $\boldsymbol{r}$. For bearings tested to failure or the $\boldsymbol{L}_{50}$ life, whichever comes first, the number of bearings to be tested $\boldsymbol{n}$ equals $2 \boldsymbol{r}$. Where testing is conducted to failure or the $\boldsymbol{L}_{50}$ life, whichever comes first, and then terminated when a predetermined number of failures $\boldsymbol{r}$ is achieved, the number of bearings to be tested $\boldsymbol{n}$ is equal to or less than $2 \boldsymbol{r}$.

For purposes of example, assume that the required number of failures to satisfy a required reliability is 9 . From Table 5, the bearing test time and calendar time are obtained for sudden death testing and sequential testing as well as the failure index (the number of failures $\boldsymbol{r}$ out of those tested $\boldsymbol{n}$ ) for 4 and 8 testers, respectively, that are operated simultaneously. These data are summarized in Table 6. Additionally, 10 Monte Carlo simulations were conducted using censored sequential testing where 4 and 8 testers run simultaneously to obtain 9 failures. For each group of testers under the column titled "Censored Sequential Testing," the first line represents the maximum time required to obtain 9 failures out of 18 bearings tested where all bearings are run to failure or the $\boldsymbol{L}_{\mathbf{5 0}}$ life, whichever comes first. The second line represents the minimum time from the 10 Monte Carlo trials where testing was conducted to failure or the $\boldsymbol{L}_{\mathbf{5 0}}$ life, whichever comes first, and then terminated when the 9 failures were obtained.

The data from Table 6 are normalized to the bearing test time for sudden test testing for four testers in Figure 5. From these data it becomes apparent that sudden death testing requires more bearing test time and calendar time then just testing nine bearings sequentially to failure. However, it may be reasonably argued that the differences in time are not significant. It can further be argued that using sudden death testing assures the required number of failures while testing only nine bearings will not assure that nine bearings will fail, within a reasonable calendar time.

Where censored sequential testing of all 18 bearings to failure or the $\boldsymbol{L}_{50}$ life to obtain nine failures is employed, there is a reduction of bearing test time and calendar time from those values obtained from sudden death testing. However, these reductions in time are not significant.

Table 6.- Summary comparison of bearing and calendar time for various methods.

\begin{tabular}{|c|c|c|c|c|c|c|c|c|c|}
\hline \multirow{2}{*}{$\begin{array}{l}\text { No. of } \\
\text { simultaneous } \\
\text { operated } \\
\text { testers }\end{array}$} & \multicolumn{3}{|c|}{ Sudden death testing } & \multicolumn{3}{c|}{ Sequential testing } & \multicolumn{3}{c|}{ Censored sequential testing } \\
\cline { 2 - 10 } & Failure & $\begin{array}{c}\text { Bearing } \\
\text { test time, } \\
\text { hrs. }\end{array}$ & $\begin{array}{c}\text { Calendar } \\
\text { time, hrs. }\end{array}$ & $\begin{array}{c}\text { Failure } \\
\text { index }\end{array}$ & $\begin{array}{c}\text { Bearing } \\
\text { test time, } \\
\text { hrs. }\end{array}$ & $\begin{array}{c}\text { Calendar } \\
\text { time, hrs. }\end{array}$ & $\begin{array}{c}\text { Failure } \\
\text { index }\end{array}$ & $\begin{array}{c}\text { Bearing } \\
\text { test time, } \\
\text { hrs. }\end{array}$ & $\begin{array}{c}\text { Calendar } \\
\text { time, hrs. }\end{array}$ \\
\hline 4 & $9 / 36$ & $\begin{array}{c}516.7 \times 10^{3} \\
---\end{array}$ & $\begin{array}{c}129.2 \times 10^{3} \\
--\end{array}$ & $9 / 9$ & $429.4 \times 10^{3}$ & $516.7 \times 10^{3}$ & $9 / 18$ & $479.6 \times 10^{3}$ & $119.9 \times 10^{3}$ \\
$9 / 15$ & -- & & $319.6 \times 10^{3}$ & $79.9 \times 10^{3}$ \\
\hline 8 & $9 / 72$ & $535.6 \times 10^{3}$ & $67.0 \times 10^{3}$ & $9 / 9$ & $429.4 \times 10^{3}$ & $516.7 \times 10^{3}$ & $9 / 18$ & $516.7 \times 10^{3}$ & $60.0 \times 10^{3}$ \\
& -- & -- & -- & -- & -- & -- & $9 / 13$ & $347.8 \times 10^{3}$ & $43.5 \times 10^{3}$ \\
\hline
\end{tabular}


From Table 6 and Figure 5 it is apparent that reductions as much as 40 percent in both bearing test time and calendar time can be achieved when compared to sudden death testing by testing to failure or the $\boldsymbol{L}_{50}$ life, whichever comes first, and then terminating all testing when the last of the nine failures has occurred. Hence, for required test data reliability, sudden death testing is not a more efficient method to reduce bearing test time or calendar time as compared to sequential testing for a required reliability (accuracy and precision).

These studies were conducted to provide guidance for endurance testing, planning, and execution. Optional test plans will depend on the constraints of a particular project such as relative costs of specimens and testing, number of specimens available, and project objectives.

\section{SUMMARY OF RESULTS}

Monte Carlo simulation combined with sudden death testing were used to compare resultant bearing lives to the calculated bearing life and the cumulative test and calendar test time relative to sequential and censored sequential testing. A total of 30960 virtual bearings of 50-mm bore deep-groove ball bearings were evaluated in 33 different sudden death test configurations compromising 36, 72, and 144 bearings each. The resultant variations in life and Weibull slope were also compared to results obtained from Monte Carlo (virtual) testing of entire populations of up to 1000 bearings and to 51 sets of actual ball and roller bearing data. The following results were obtained:

1. For sudden death testing and sequential testing, variations in both life and Weibull slope were a function of the number of bearings failed independent of the test method used and not the total number of bearings tested. Variations in $\boldsymbol{L}_{\mathbf{1 0}}$ life as a function of number of bearings failed were similar to variations in life obtained from actual bearing data and from Monte Carlo (virtual) testing of entire populations.

2. To achieve a predetermined number of failures for a required reliability, reductions as much as 40 percent in both bearing test time and calendar time can be achieved when compared to sudden death testing by testing to failure or the $\boldsymbol{L}_{\mathbf{5 0}}$ life, whichever comes first, and then terminating all testing when the last of the predetermined bearing failures has occurred.

3. For required test data reliability, sudden death testing is not a more efficient method to reduce bearing test time or calendar time when compared to censored sequential testing. However, sudden death testing will assure that with reasonable certainty a predetermined number of failures will occur.

\section{REFERENCES}

1. Johnson, L.G. (1964), The Statistical Treatment of Fatigue Experiments, Elsevier Publishing Co., Amsterdam.

2. Vlcek, B.L., Hendricks, R.C., and Zaretsky, E.V. (2003), "Determination of Rolling-Element Fatigue Life From Computer Generated Bearing Tests,” STLE Trib. Trans., 46, 4.

3. Zaretsky, E.V., Parker, R. J., and Anderson, W.J. (1982), NASA Five-Ball Fatigue Tester-Over 20 Years of Research” in Rolling Contact Fatigue Testing of Bearing Steels, American Society of Testing Materials, Philadelphia, ASTM STP 771, pp. 5-45.

4. Houpert, L. (2003), “An Engineering Approach to Confidence Intervals and Endurance Test Strategies,” Trib. Trans., 46, 2, pp 248-259.

5. O'Brien, M.J., Presser, N., and Robinson E.Y. (2003), "Failure analysis of three Si3N4 balls used in hybrid bearings," Engineering Failure Analysis, 10, pp 453-473.

6. Harris, T. (1990), Rolling Bearing Analysis—-3 $3^{\text {rd }}$ Edition, ch. 3, John Wiley and Sons, New York.

7. McCool, J. (1982), "Analysis of Sets of Two-Parameter Weibull Data Arising in Rolling Contact Endurance Testing," in Rolling Contact Fatigue Testing of Bearing Steels, American Society of Testing Materials, Philadelphia, ASTM STP 771, pp. 293-319.

8. Pascual, F. and Meeker, W. (1998), "The Modified Sudden Death Test: Planning Life Tests With Limited Number of Test Positions,” J. Test. Eval., 26, 5, pp 434-443.

9. Lundberg, G. and Palmgren, A. (1947), "Dynamic Capacity of Rolling Bearings,” Acta Polytechnica, 1, 3.

10. Harris, T.A. (1995), "Final Report-Establishment of a New Rolling Bearing Contact Life Calculation Method," Contract No. N68335-93-C-0111, U.S. Naval Air Warfare Center, Aircraft Division Trenton. 
11. Harris, T.A. and McCool, J.I. (1996), "On the Accuracy of Rolling Bearing Fatigue Life Prediction,” ASME Jour. Of Tribology, 118, 2, pp 297-310.

12. Weibull, W. (1939), "A Statistical Theory of the Strength of Materials," Ingeniorsvetanskapsakad Handl., 151.

13. Weibull, W. (1951), "A Statistical Distribution Function of Wide Applicability," ASME Jour. Of Applied Mechanics, 18, 3, 1951, pp. 293-297.

14. Weibull, W. (1939), “The Phenomenon of Rupture on Solids,” Ing. Vetenskaps Akad., 153.

15. Zaretsky, E.V. (1992), STLE Life Factors for Rolling Bearings, Society of Tribologists and Lubrication Engineers, Park Ridge, IL, STLE SP-34, pp 1-45 and pp 233-298.

16. Krantz, T. (2002), "The Influence of Roughness on Gear Surface Fatigue,” Ph.D. Thesis, Case Western Reserve University, Cleveland.

17. Cohen, C. (1965), "Maximum Likelihood Estimation in the Weibull Distribution Based on Complete and on Censored Samples," Technomet., 7, 4, pp 579-588.

18. Skinner, K., Keates, J., and Zimmer, W. (2001), "A Comparison of Three Estimators of the Weibull Parameters,” Quality and Reliability Engineering International, 17, pp 249-256. 


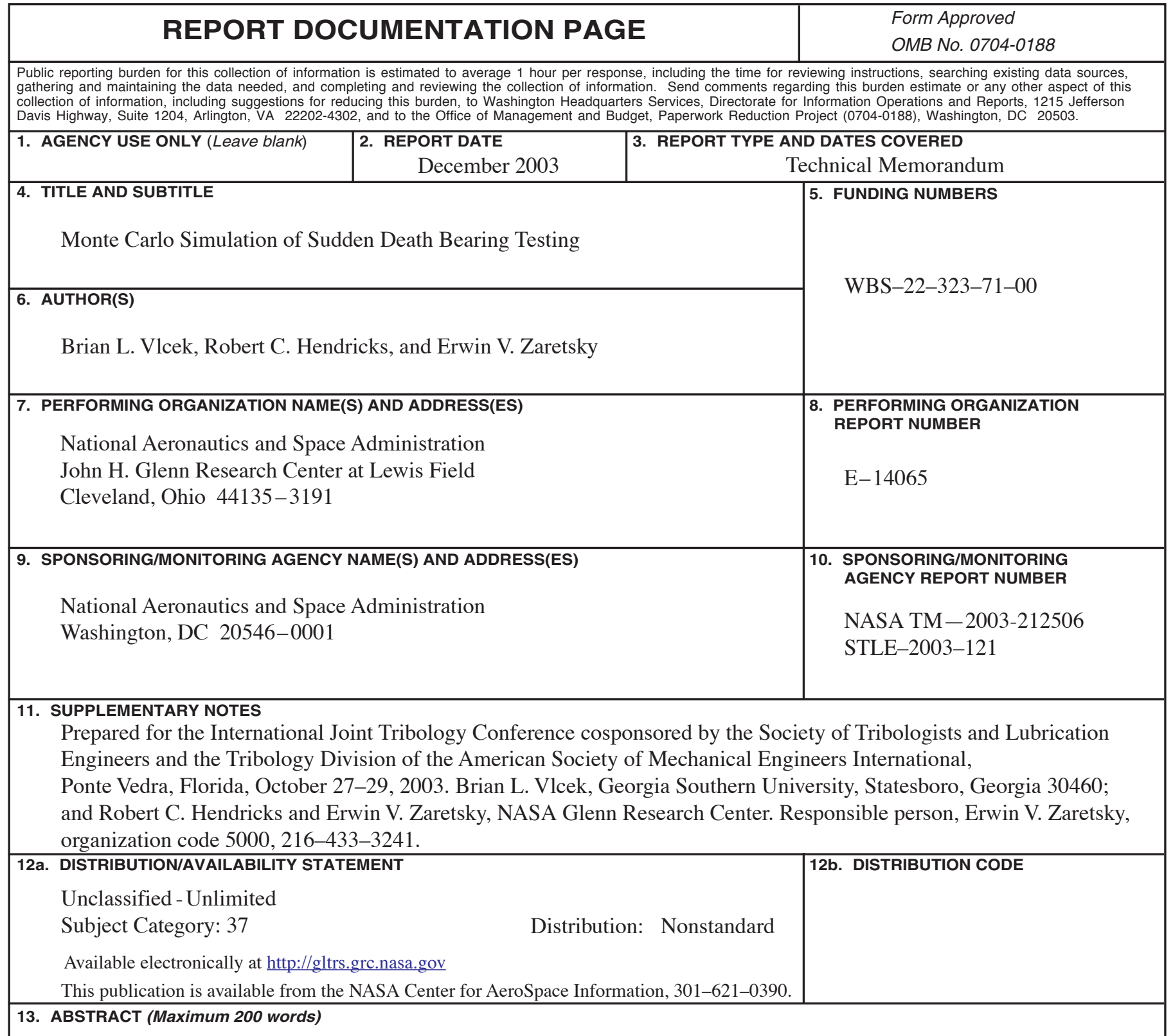

Monte Carlo simulations combined with sudden death testing were used to compare resultant bearing lives to the calculated hearing life and the cumulative test time and calendar time relative to sequential and censored sequential testing. A total of 30960 virtual 50-mm bore deep-groove ball bearings were evaluated in 33 different sudden death test configurations comprising 36, 72, and 144 bearings each. Variations in both life and Weibull slope were a function of the number of bearings failed independent of the test method used and not the total number of bearings tested. Variation in $L_{10}$ life as a function of number of bearings failed were similar to variations in lift obtained from sequentially failed real bearings and from Monte Carlo (virtual) testing of entire populations. Reductions up to 40 percent in bearing test time and calendar time can be achieved by testing to failure or the $L_{50}$ life and terminating all testing when the last of the predetermined bearing failures has occurred. Sudden death testing is not a more efficient method to reduce bearing test time or calendar time when compared to censored sequential testing.

\begin{tabular}{|c|c|c|c|}
\hline \multicolumn{3}{|l|}{ 14. SUBJECT TERMS } & 15. NUMBER OF PAGES \\
\hline \multirow{2}{*}{\multicolumn{3}{|c|}{$\begin{array}{l}\text { Rolling-element bearings; Life prediction; Weibull analysis; Sudden death testing; } \\
\text { Computer simulation; Monte Carlo analysis }\end{array}$}} & 22 \\
\hline & & & 16. PRICE CODE \\
\hline $\begin{array}{l}\text { 17. SECURITY CLASSIFICATION } \\
\text { OF REPORT }\end{array}$ & $\begin{array}{l}\text { 18. SECURITY CLASSIFICATION } \\
\text { OF THIS PAGE }\end{array}$ & $\begin{array}{l}\text { 19. SECURITY CLASSIFICATION } \\
\text { OF ABSTRACT }\end{array}$ & 20. LIMITATION OF ABSTRACT \\
\hline Unclassified & Unclassified & Unclassified & \\
\hline
\end{tabular}

